\title{
Selection of Optimum Vegetative Indices for the Assessment of Tobacco Float Seedlings Response to Fertilizer Management
}

\author{
Ezekia Svotwa, ${ }^{1}$ Barbara Maasdorp, ${ }^{2}$ Amon Murwira, ${ }^{3}$ and Anxious Masuka ${ }^{1}$ \\ ${ }^{1}$ Tobacco Research Board, Kutsaga Research Station, P.O.Box 1909, Harare, Zimbabwe \\ ${ }^{2}$ Department of Crop Science, University of Zimbabwe, Harare, Zimbabwe \\ ${ }^{3}$ Department of Geography and Environmental Studies, University of Zimbabwe, Harare, Zimbabwe
}

Correspondence should be addressed to Ezekia Svotwa, esvotwa2@gmail.com

Received 13 April 2012; Accepted 21 May 2012

Academic Editors: M. Arias-Estévez, O. Merah, and M. A. Taboada

Copyright () 2012 Ezekia Svotwa et al. This is an open access article distributed under the Creative Commons Attribution License, which permits unrestricted use, distribution, and reproduction in any medium, provided the original work is properly cited.

\begin{abstract}
The experiment sought to establish the vegetative indices for assessing tobacco float seedling varieties' response to different fertilizer rates. A factorial design, with 3 variety $\times 4$ fertilizer management treatments, was used. The $\mathrm{N}: \mathrm{P}: \mathrm{K}$ treatments were applied at 7 , 21 , and 35 days after sowing, while $\mathrm{N}$ treatments were applied at 42 days. Radiometric measurements were taken at 49,56, 64, and 79 days after sowing on 8 tray plots, using a multispectral radiometer. Mature seedling samples were harvested at day 79 and stem lengths were determined before processing for total $\mathrm{N}$ analysis. All the five channels of the radiometer, the NDVI, and the SRI had a strong relationship with fertiliser rate. Both the NDVI and SRI for T66 were greater $(P<0.05)$ than those for KRK26 and KE1. The SRI had a stronger relationship with seedling dry mass, seedling count/tray, and stem length than the NDVI. The NDVI also showed a stronger relationship with total $\mathrm{N}$ than the SRI. The minimum threshold SRI and NDVI values and optimum growth (100\% fertilser) were 0.72 and 6.1 . This information is useful in identifying and estimating tobacco seedbed area and seedling vigour using remote sensing and, therefore, is important in forecasting potential tobacco crop area and yield.
\end{abstract}

\section{Background}

Nutrient stress adversely affects seedling growth vigour, productivity, and overall quality. Early detection of nutrient stress in crops facilitates the timely application of corrective cultural practices before stress adversely affects seedling yield and quality [1]. Tobacco growers visually monitor seedlings for nutrient stress symptoms. A possible alternative to visual seedling health monitoring is the use of optical sensors that rely on light to assess the physiological status either at the leaf or canopy level.

A leaf nitrogen concentration is an important indicator of plant fertilizer requirements. Nitrogen $(\mathrm{N})$ is a constituent of chlorophyll, the green colouring matter in plants that plays a role in absorbing light for photosynthesis [2]. Nitrogen deficiency in tobacco plants decreases chlorophyll and soluble protein content, causing a progressive loss in green colour starting in the older leaves. The affected crop lacks in texture, with much lower nitrogen and nicotine content and a reduction in the rate of leaf expansion and canopy development [3, 4]. Excessive nitrogen results in large, darkgreen leaves [2].

Plant nitrogen status influences chlorophyll content. Researchers on ways of using remote sensing in quantifying plant nitrogen status have targeted pigment-based reflectance indices or the position of the chlorophyll red-edge [5], since pigment-induced crop reflectance is dominated by chlorophyll [6]. Canopy reflectance has the potential to rapidly estimate tobacco seedling $\mathrm{N}$ status, and hence seedling vigour and quality. It is important that the detection of plant $\mathrm{N}$ status is done at an early stage of crop development and this requires identification of spectral wavebands or indices in which vegetation reflectance is most responsive to unfavorable growth conditions.

Remote sensing in the visible and near-infrared (NIR) wavelengths (400 and $1000 \mathrm{~nm}$ ) is based on the principle that changes in plant light interception and utilization are influenced by plant cell chemical composition and canopy structure [7]. A plant leaf typically has a low reflectance in 
the visible spectral region because of strong absorption by chlorophylls, a relatively high reflectance in the near-infrared because of internal leaf scattering and no absorption, and a relatively low reflectance in the infrared beyond $1.3 \mu$ because of strong absorption by water $[8,9]$. The peak at the green region gives rise to the green colour of vegetation. The leaves of a given plant species tend to have a characteristic surface, thickness, internal structure, and pigment content. Similarly, the canopy's horizontal and vertical extents tend to have a characteristic structure, which is determined by the size, shape, and orientation of the plants and their leaves and by the cultural practices or environmental growing conditions. All these factors influence the leaf and canopy optical properties and the reflection patterns received by sensors represent the integration of their effects [10].

The reflectance at plant canopy level is similar, but is slightly modified by the nonuniformity of incident solar radiation, plant structures, leaf areas, shadows, and background reflectivity according to [11]. Airborne sensors receive an integrated view of all these effects, and each crop or vegetation type tends to have a characteristic signature which enables its identification, and possibly, species response to environmental factors like moisture, nutrient, and disease [8].

Vegetation indices (VIs) are combinations of surface reflectance at two or more wavelengths. These indices are designed to highlight a particular property of vegetation [10]. By comparing the results of different VIs and correlating these to field conditions, one can determine the indices that best correlate with crop agronomic parameters of interest [12]. VIs compares reflectance in the near-infrared range to another measurement taken in the visible.

The rationale for spectral vegetation indices (VIs) is to exploit the different spectral signatures for green vegetation as compared to spectral signatures of other earth materials. Green leaves have a distinct spectral reflectance pattern in the visible (VIS) and near-infrared (NIR) wavelengths. Reflectance in the blue and red regions is very low and higher in the green region. This is why leaves appear green to human eyes. Other materials such as bare soil, sand, exposed rock, concrete, or asphalt, generally show a linear relationship between reflectance and the five wave bands and this is due to steady rise in reflectance as wavelength increases from the visible to the near-infrared. Most VIs compare the differences between the red and near-infrared reflectance. Red (or visible) reflectance is sensitive to chlorophyll content and the near-infrared reflectance is sensitive to the mesophyll structure and leaf compositions. The greater the difference between the red (or visible) and near-infrared reflectance, the greater the amount of green vegetation present. Small differences between the red (or visible) and near-infrared reflectance indicate the influence of different plant stress, background material such as soil or other nongreen materials. Spectral vegetation indices are related to a number of biophysical parameters including Leaf Area Index (LAI), percent vegetation cover, green leaf biomass, and fraction of absorbed photosynthetically active radiation (fAPAR $[13,14]$ and can be used as alternative tool for estimating $\mathrm{N}$ status [15]).
The most commonly used VI is the Normalized Difference Vegetation Index (NDVI). The NDVI has been in use for many years to measure and monitor plant growth (vigor), vegetation cover, and biomass production from multispectral satellite data $[10,11]$. The index is calculated using the formula: NDVI $=(\mathrm{NIR}-\mathrm{Red}) /(\mathrm{NIR}+\mathrm{Red})$. As described by Jackson et al. [10], the index is considered a good indicator of amount of vegetation and, hence, useful in distinguishing vegetation from soil.

The Simple Ratio (SR) Index, another well-known VI, is defined by the equation: SR = NIR/R [16]. The index becomes high with increasing vegetative density and plant health, thus indicating the amount of biomass. The value of this index for green vegetation ranges from 2 to 8 , according to Eitel et al. [11]. Other indices are the Blue Normalized Difference Vegetative Index, Green Vegetative Index, Chlorophyll Index, and the Nitrogen Reflectance Index [17].

This research seeks to identify suitable reflectance ratios for assessing the nutrient status, vigour, quality, and quantity of tobacco seedlings in the seedbed. The information will be useful in identifying tobacco seedbeds, estimation of tobacco seedbed area as well as seedling vigour using remote sensing and, therefore, it is important in forecasting tobacco crop yield using remote sensing. Tobacco yield estimation in Zimbabwe has been based on the Garvin model [18], seed tracking approach and the statistical and crop condition assessment approaches. These traditional methods are tedious and time consuming and are based on data collected from sampled area and, hence, the precision of the methods is varied [18]. A more objective and practical model for yield estimation could assist tobacco stakeholders with more precise data on tobacco hectarage and yield that would be available for export.

By using satellite imagery instead of traditional sampling techniques, crop yield forecasts can be generated earlier than traditional estimates, and because they are based on images that are constantly being downloaded from the satellite, these forecasts can be updated frequently throughout the growing season. Remote sensing enables observations over large areas at regular intervals, making it useful in large-scale crop modeling $[19,20]$. Use of satellite imagery would also enable the verification farmers' claims of seedbed area established.

\section{Method}

The experiment was carried out in the floatbed between June 2010 and September 2012 at Kutsaga Research Station, near Harare in Zimbabwe. Kutsaga is located $16 \mathrm{~km}$ to the South East of the capital, Harare, between Longitude $31^{\circ} 08^{\prime} \mathrm{E}$, Latitude $17^{\circ} 55^{\prime} \mathrm{S}$, and at an altitude of $1000 \mathrm{~m}$ to $1500 \mathrm{~m}$ (TRB, 1986). The long-term annual average rainfall for the site is $850 \mathrm{~mm}$. The annual average temperature is $18.6^{\circ} \mathrm{C}$ and the range average monthly temperature is $8^{\circ} \mathrm{C}$.

2.1. Fertilizer Treatments. A factorial design, with 3 variety $\times$ 4 fertiliser management treatments, was used. Three Kutsaga tobacco varieties, T66, KRK26, and KE1, were used. The fertilizer treatments were applied by hands as shown in Table 1 below. The $\mathrm{N}: \mathrm{P}: \mathrm{K}$ treatments were hand-applied in 
TABLE 1: Variety $\times$ fertilizer treatments.

\begin{tabular}{|c|c|}
\hline Variety & Fertilizer level \\
\hline \multirow{4}{*}{ K RK 26} & $0 \%$ \\
\hline & $50 \%$ \\
\hline & $100 \%$ \\
\hline & $150 \%$ \\
\hline \multirow{4}{*}{ Т 66} & $0 \%$ \\
\hline & $50 \%$ \\
\hline & $100 \%$ \\
\hline & $150 \%$ \\
\hline \multirow{4}{*}{ KE 1} & $0 \%$ \\
\hline & $50 \%$ \\
\hline & $100 \%$ \\
\hline & $150 \%$ \\
\hline
\end{tabular}

float water at 7,21 , and 35 days after planting in the form of Floatfert (4.5 2.7 4.2), while $\mathrm{N}$ treatments were applied at 42 days after planting. The recommended Floatfert rate of $6 \mathrm{~L} / \mathrm{ha})$ is applied at $7(1 \mathrm{~L}), 21(2 \mathrm{~L})$, and 35 days $(3 \mathrm{~L})$. Ammonium nitrate $(34.5 \% \mathrm{~N})$, a nitrogen source is applied at $800 \mathrm{~g} / \mathrm{ha}$ equivalent. Each plot had sixteen 242 -cell float trays each measuring $67 \mathrm{~cm} \times 34.5 \mathrm{~cm}$ and, of these, 8 central trays were assessed.

2.2. Procedure. Radiometric measurements made on 8 tray plots, using a hand held multispectral radiometer (Cropscan MSR-5, 450-1750 nm). The radiometer simultaneously measures irradiance and radiance to provide canopy surface reflectance. The data acquired represents the average reflection from the area sampled. Normalized Difference Vegetation Index (NDVI) values calculated using the reflectance measured from Channel 3 (visible: $630-690 \mathrm{~nm}$ ) and Channel 3 (near infrared: $760-900 \mathrm{~nm}$ ) were used to calculate the index:

$$
\mathrm{NDVI}=\frac{(\mathrm{Ch} 4-\mathrm{Ch} 3)}{(\mathrm{Ch} 4+\mathrm{Ch} 3)}
$$

The Multispectral Radiometer (MRS 5) was positioned facing vertically downward at $1 \mathrm{~m}$ above seedling canopies, and measurements were taken around solar noon to minimize the effect of diurnal changes in solar zenith angle. Ten (10) measurements were taken per sampling area and reflectance measurements were averaged for each sampling plot to estimate a single reflectance value. Seedlings in each tray were counted and mature seedling samples were harvested at 79 days after sowing. Seedling stem lengths were also determined at pulling before samples were dried and ground for laboratory total nitrogen measurements using the Kjeldahl method.

2.3. Data Analysis. Spectral data was analyzed using Genstat 9.2 Edition (2007), while graphs were constructed using Excel 2007.

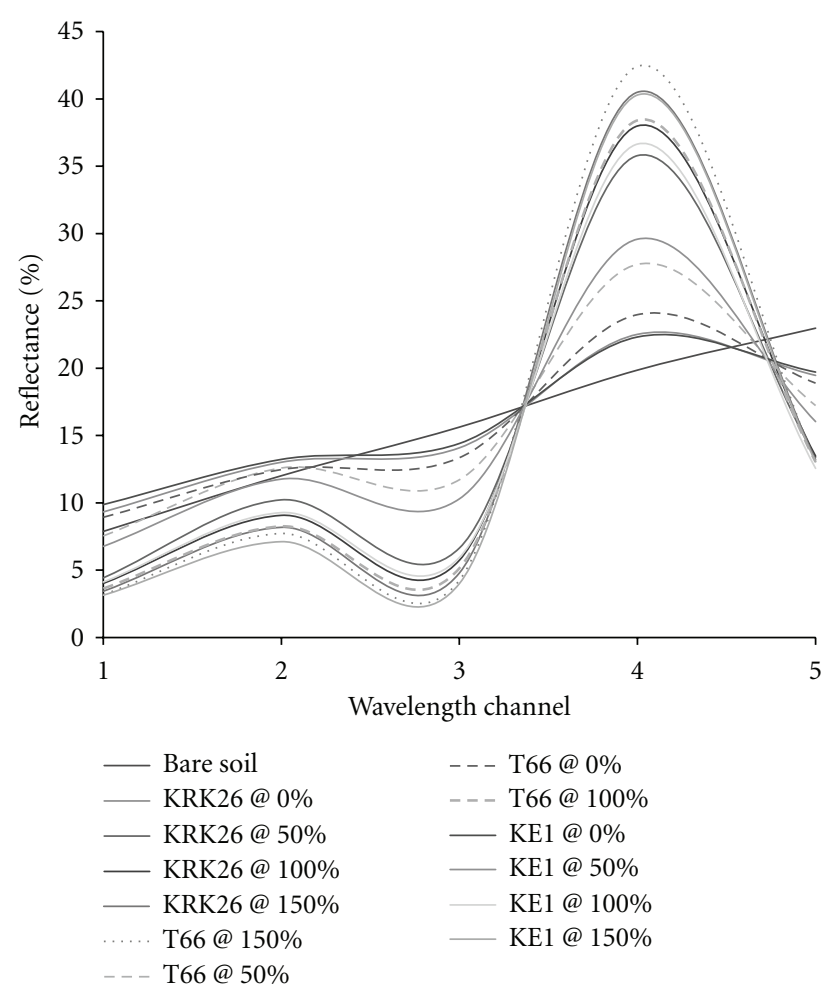

FIGURE 1: Spectral reflectance signatures for the variety fertilizer of treatments.

\section{Results}

3.1. Seasonal Average Spectral Reflectance for the Variety $\times$ Fertilizer Treatments. Seasonal average reflectance values were used to plot the spectral response curve (Figure 1). All varieties displayed a similar S-shaped spectral reflectance signature with peaks at Channel $2(520-600 \mathrm{~nm})$ and Channel $4(760-900 \mathrm{~nm})$, and dips at Channel 1 (450$520 \mathrm{~nm}), 3(630-690 \mathrm{~nm})$ and $5(1550-1750 \mathrm{~nm}$ ) (Figure 6). The spectral signature for bare soil was more or less straight with less pronounced peaks and dips.

Channel $1(450-520 \mathrm{~nm})$ reflectance values were negatively correlated with rate of fertilizer application $\left(r^{2}=\right.$ $-0.858)$. KE1 at $0 \%$ recommended fertilizer had the highest reflectance on Channel 1 (9.869). Reflectance values for the other varieties for the same $(0 \%)$ fertilizer treatment were 9.32 (K RK 26) and 8.92 (T66). Percentage reflectance decreased as the rate of fertilizer application increased, reaching the lowest level at $150 \%$ recommended fertilizer. KE1 at $150 \%$ of the recommended fertilizer had the lowest reflectance (3.139). Reflectance values for the other two varieties at $150 \%$ fertilizer application rate were 3.44 (KRK 26) and 3.18 (T66).

Channel 2 (520-600 mm) (Figure 2), Channel 3 $(630-690 \mathrm{~nm})$ (Figure 3), and Channel $5(1550-1750 \mathrm{~nm})$ (Figure 4) followed the same pattern as Channel 1 (450$520 \mathrm{~nm}$ ), showing a negative correlation with the rate of fertilizer application $\left(r^{2}=0.90,0.874\right.$ and 0.769 , resp. $)$. 


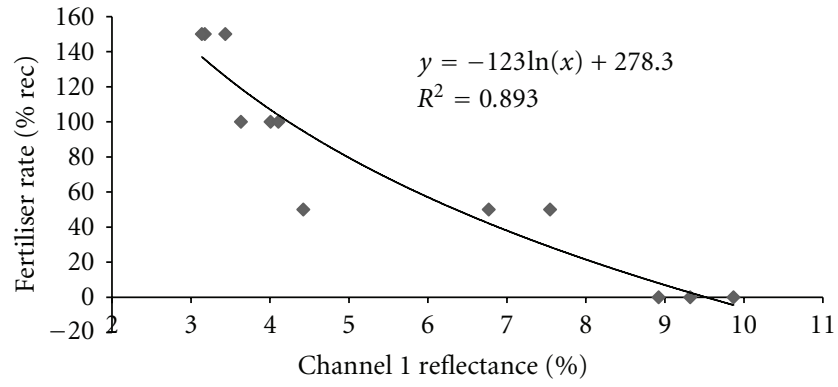

FIgUre 2: Correlation between fertilizer rate (\%) and Channel 1 (450-520 $\mathrm{nm})$ reflectance values.

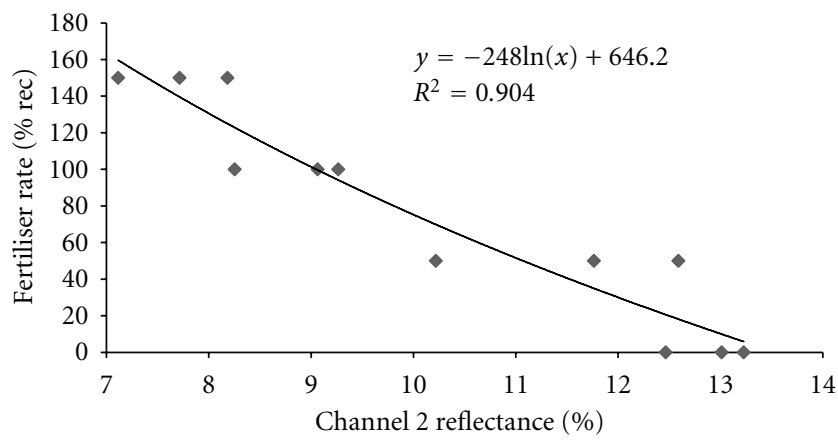

Figure 3: Correlation between fertilizer rate (\%) and Channel 2 $(520-600 \mathrm{~nm})$ reflectance values.

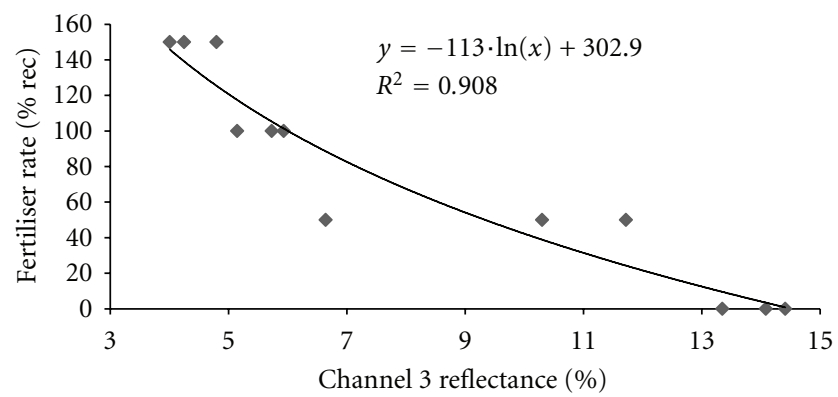

FIGURE 4: Correlation between fertilizer application rate (\%) and Channel 3 (630-690 nm) reflectance values.

Channel $4(760-900 \mathrm{~nm})$ reflectance values are positively correlated with rate of fertilizer application $\left(r^{2}=0.904\right)$ (Figure 5). Percentage reflectance increased as the rate of fertilizer increased from $0 \%$, reaching the highest at $150 \%$ recommended fertilizer. T66 at 150\% recommended fertilizer had the highest reflectance value (42.414). Other Channel 4 reflectance values at $150 \%$ fertilizer were 40.5 (KRK26) and 40.2 (KE1). The $0 \%$ fertilizer application rates had the lowest reflectance values for all the 3 varieties $(\mathrm{KRK} 26=22.5 ; \mathrm{T} 66=23.97$ and $\mathrm{KE} 1=22.3)$.

Both the NDVI and the SRI were positively correlated with the fertilizer application rate (Figure 7). The coefficient of determination for SR and fertilizer application rate

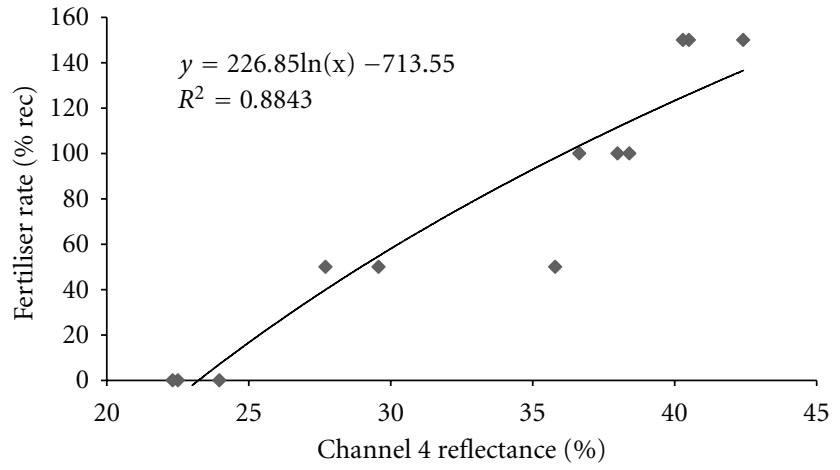

FIGURE 5: Correlation between fertilizer application rate (\%) and Channel 4 (760-900 $\mathrm{nm})$ reflectance values.

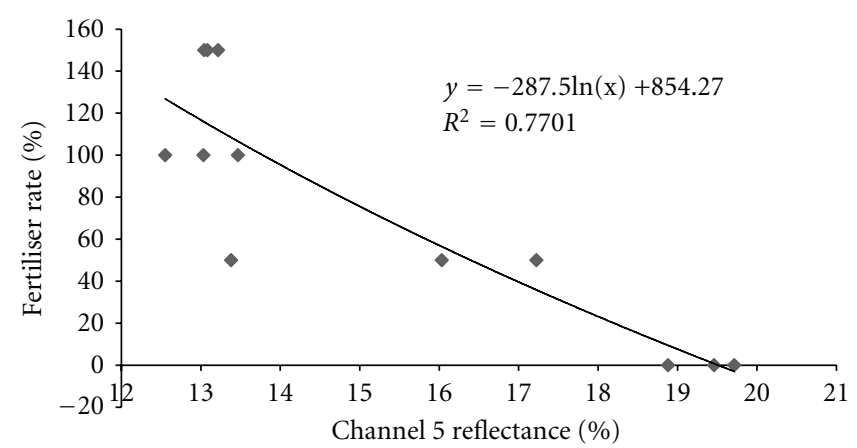

FIgure 6: Correlation between fertilizer application rate (\%) and Channel 5 (1550-1750 $\mathrm{nm}$ ) reflectance values.

$\left(r^{2}=0.905\right)$ was greater than that for NDVI and fertilizer application rate $\left(r^{2}=0.819\right)$. The differences among varieties, fertilizer application rates, and variety $\times$ fertilizer interactions were highly significant $(F=0.016)$ (Figure 10$)$.

Both the NDVI and SRI for T66 were greater $(P<0.05)$ than those for KRK26 and KE1. The latter two (KRK26 and KE1) had statistically similar $(P<0.05)$ reflectance values. There were also significant $(F<0.001)$ fertilizer application rate effect on seedling canopy reflectance $(0>0.05 \%>$ $100 \%>150 \%)$, respectively. The treatment differences in NDVI and SR indices were maintained from day 49 to day 79 , the time of pulling (Figures 8 and 9).

The correlations between seedling dry mass with both NDVI and SRI correlations were high $\left(r^{2}=0.848\right.$ and $r^{2}=0.912$ resp.) (Figure 11). The seedling count/tray versus NDVI correlation $\left(r^{2}=0.626\right)$ was lower than that of the seedling count versus SRI $\left(r^{2}=0.797\right)$ (Figure 12) and the same trend was also noted on the seedling height versus NDVI $\left(r^{2}=0.80\right)$ and seedling height versus SRI $\left(r^{2}=\right.$ $0.936)$ (Figures 13 and 14). The NDVI showed a weaker correlation $\left(r^{2}=0.72\right)$ with total $\mathrm{N}$ than the SRI $\left(r^{2}=\right.$ $0.866)$.

A summary for the NDVI and SRI ranges for the different fertilizer levels is shown in Table 2. The minimum threshold values for NDVI and SRI for good quality, transplantable, and well-nourished seedlings was 0.72 and 6.1 , respectively. 


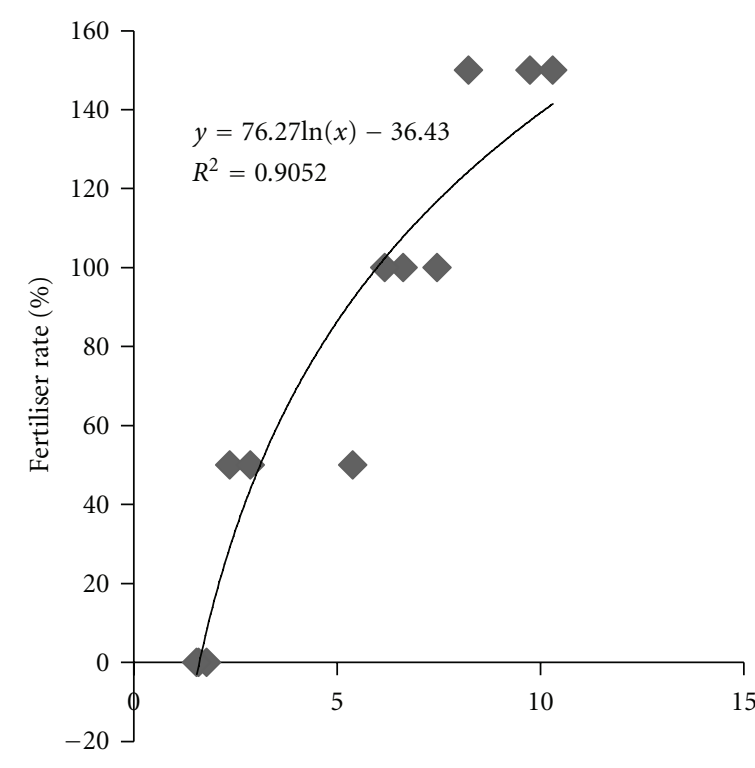

SRI

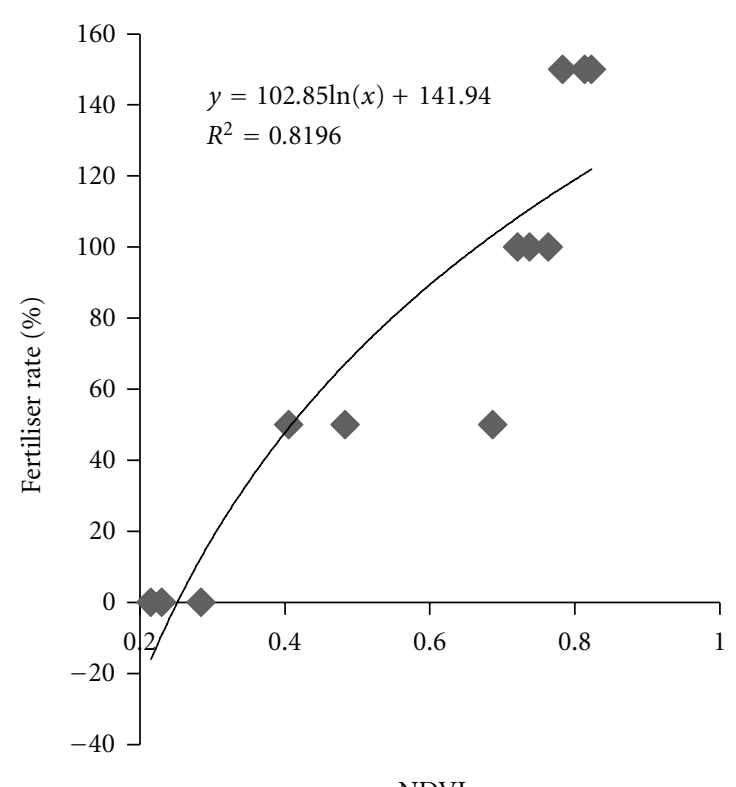

NDVI

FIGURE 7: Correlation between NDVI/SRI versus fertilizer application rate at 72 days after sowing.

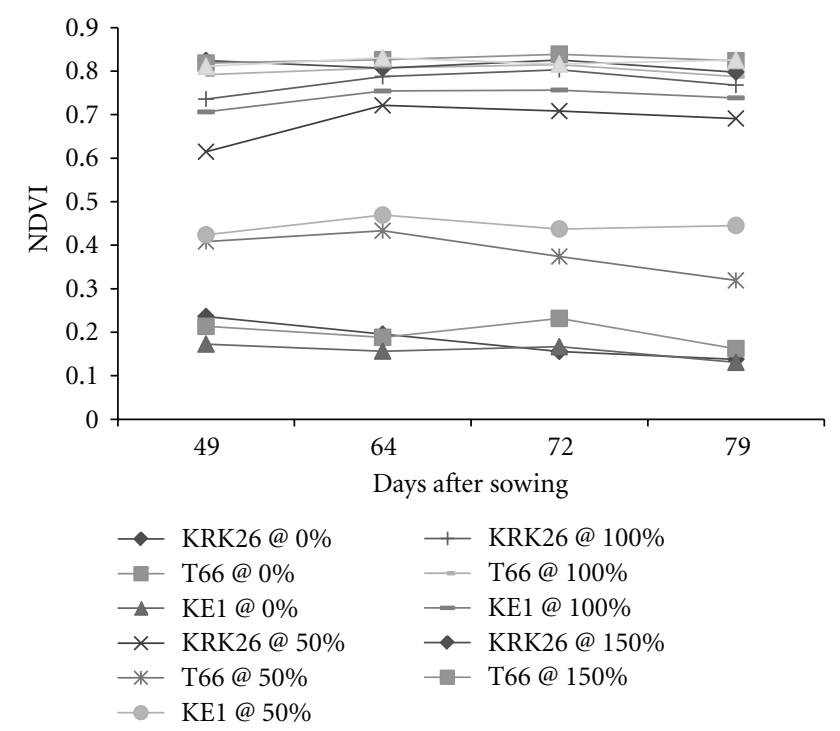

FIGURE 8: Seasonal changes in seedling reflectance (NDVI) between 49-79 days after sowing.

\section{Discussion}

The S-shaped spectral response curve produced from the seasonal average reflectance values for the variety fertilizer treatments was typical for green plants. Vegetation has a unique spectral signature which enables it to be distinguished readily from other types of land cover in an optical/nearinfrared image [12]. This characteristic was according to Nowatzki et al. [21] and Demetriades-Shah et al. [22] due to strong absorption by chlorophylls in the red region, internal leaf scattering in the near-infrared and strong absorption by water in the infrared beyond $1.3 \mu$. The reflectance of a plant

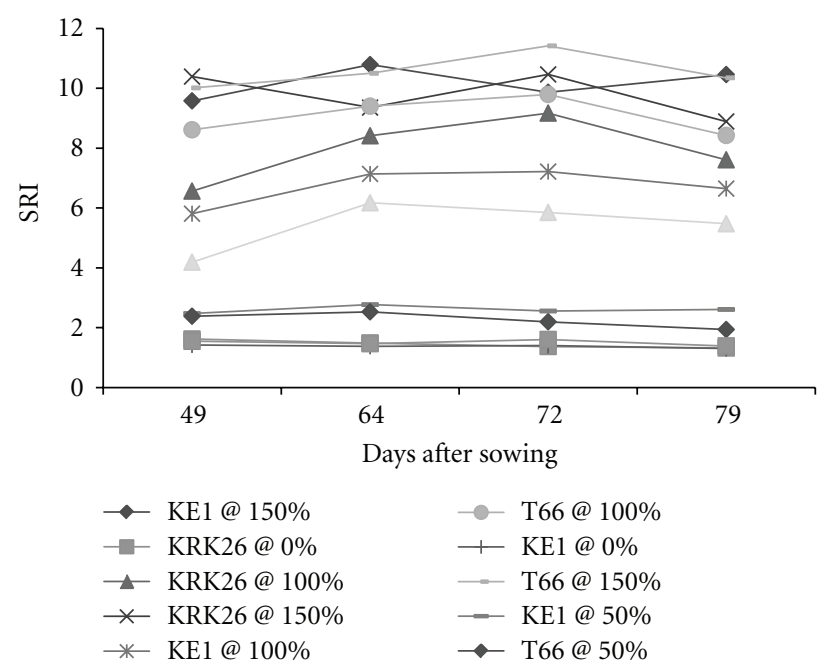

FIGURE 9: Seasonal changes in seedling reflectance (SRI) between 49-79 days after sowing.

canopy is similar, but is modified by the nonuniformity of incident solar radiation, plant structures, leaf areas, shadows, and background reflectivities [23]. Species discrimination is made possible when airborne sensors are used because these receive an integrated view of all these effects, and each crop or vegetation type tends to have a characteristic signature [8].

The lower the fertilizer application rate, the higher the Channel 1, 2, and 3 reflectance values. The reflectance values in the blue (Channel 1) and red (Channel 3) regions of the spectrum were, as suggested by Ustin et al. [24], due to high absorption by chlorophyll for photosynthesis, while the peaks observed at the green (Channel 2) region were also typical of the green colour of vegetation [25]. In the visible 

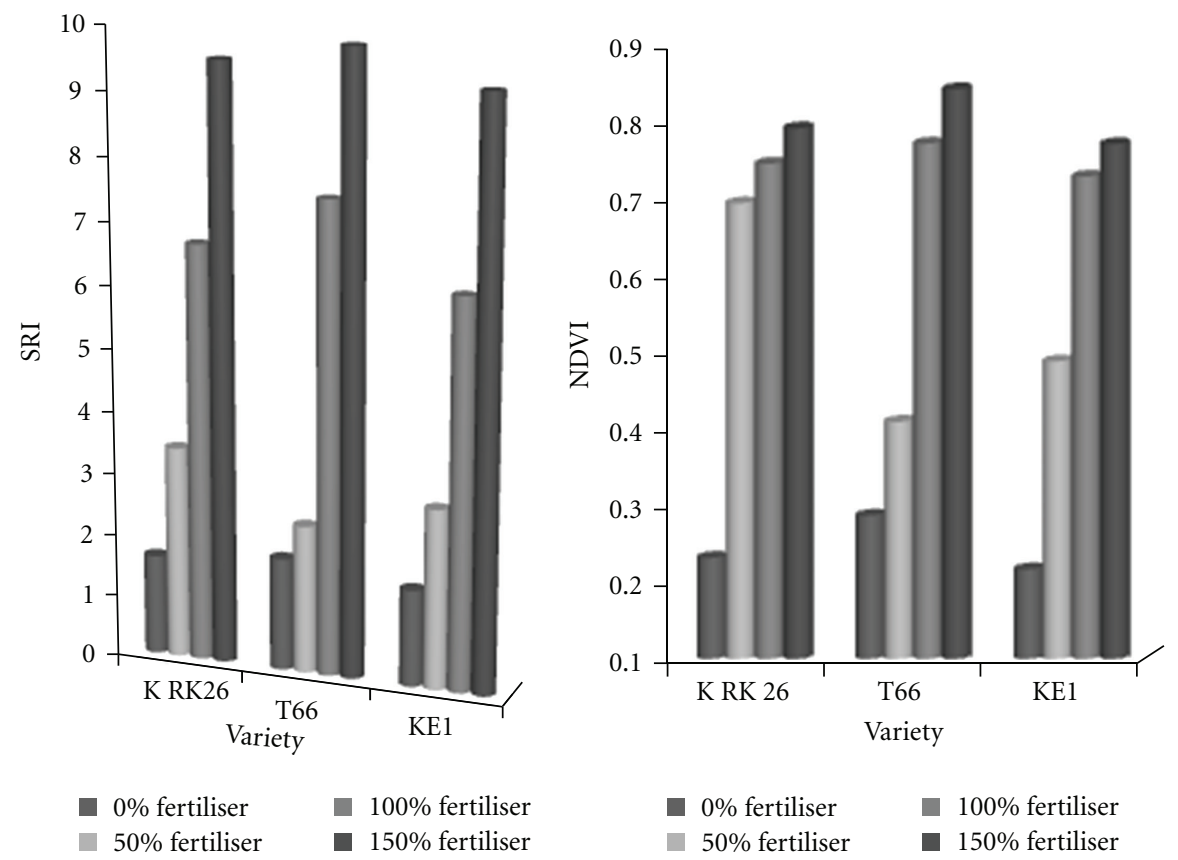

FIGURE 10: Reflectance response for the variety $\times$ fertiliser rate interactions.
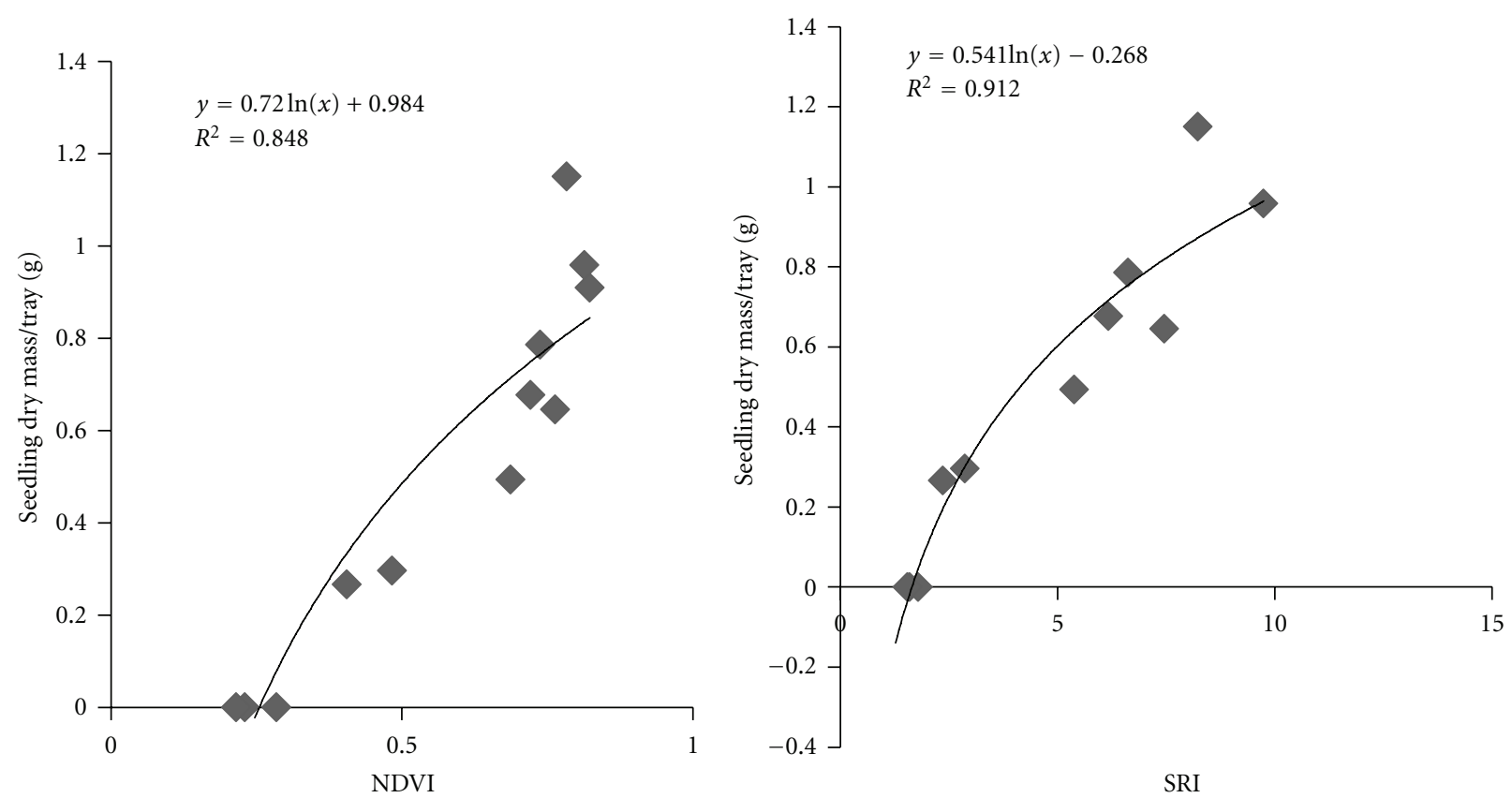

FIgURE 11: Correlation between seedling dry mass and NDVI/SRI.

spectral region, the high absorption of radiation energy is due to leaf pigments, primarily the chlorophylls, although the carotenoids, xanthophylls, and anthocyanins also have an effect $[26,27]$. Use of reflectance values for these channels, or VIs calculated from these could enable researchers to identify the health status of seedling and estimate the quantities that could transplantable.
The much higher reflectance in the near infrared (NIR) region than the visible band could be, according to Knipling [9], due to the cellular structure in the leaves that cause scattering of electromagnetic energy. Broge et al. [5] attributed the increase in the near infrared reflectance to increases of biomass and the number and size of leaf cell layers. The differences in the NIR reflectance values among varieties 


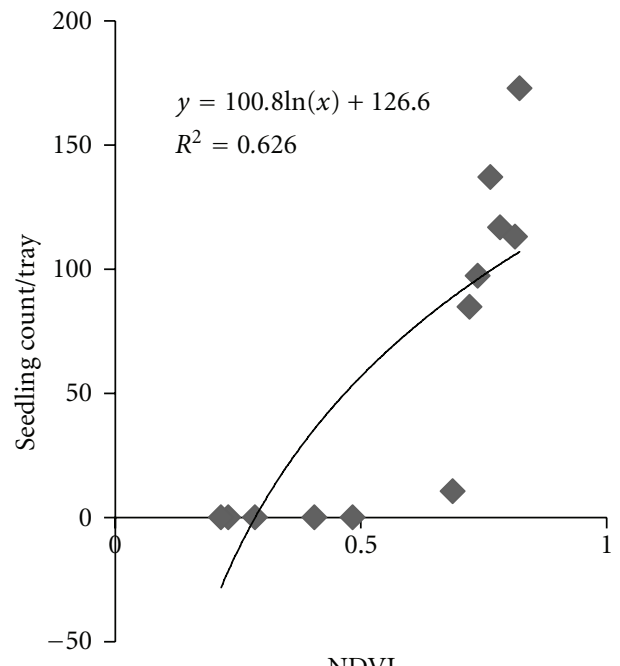

NDVI

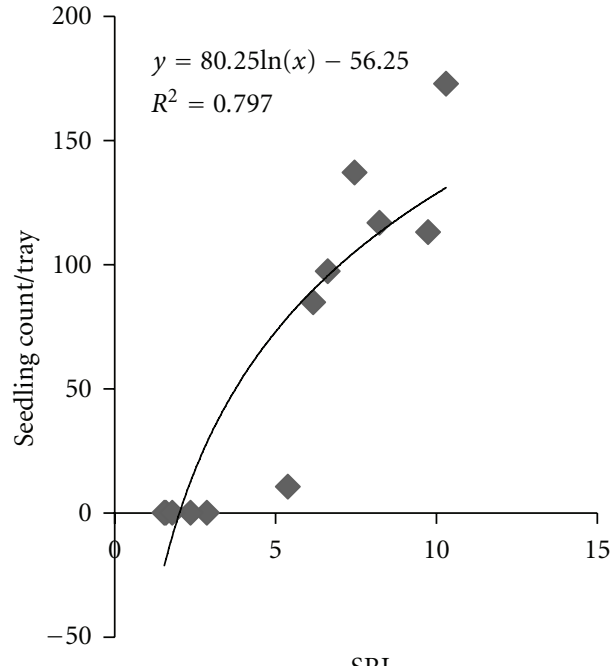

SRI

FIGURE 12: Correlation between seedling count/tray and NDVI/SRI.
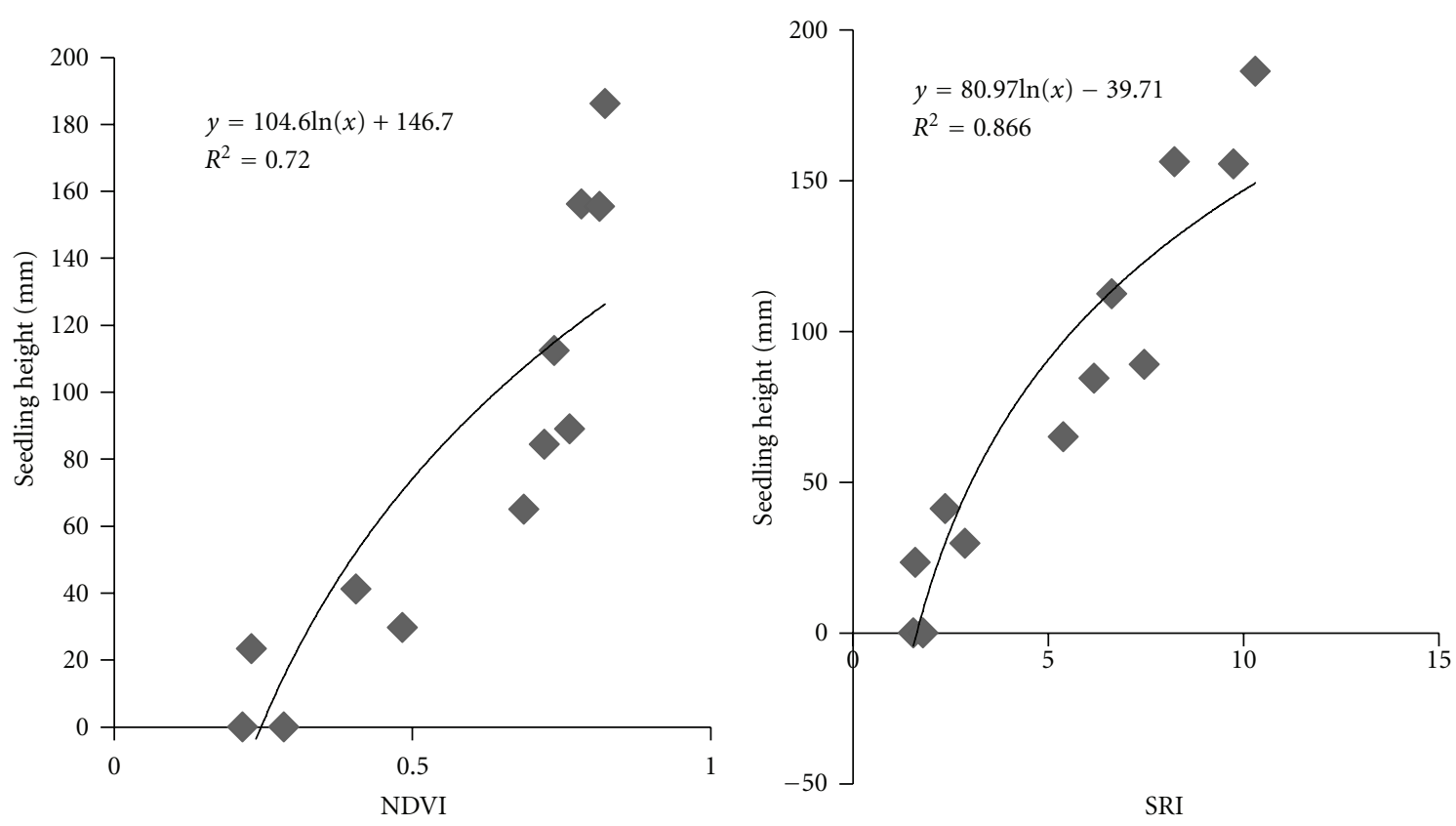

FIGURE 13: Correlation between Seedling length and NDVI/SRI.

and fertiliser treatments could be indication of varietal differences in the ability to exploit environmental resources for biomass production.

There were also significant $(F<0.001)$ fertilizer application rate effects on seedling canopy reflectance, with SRI showing a stronger relationship $\left(r^{2}=0.905\right)$ than NDVI $\left(r^{2}=0.819\right)$. Generally, the lower is the reflectance in the green and the red regions of the electromagnetic radiation, the healthier is the target vegetation. Such signatures were in this experiment, typical of higher fertilizer rates as reported by Jackson [1]. Well-managed crop canopies naturally appear as those reported by $\mathrm{Su}$ et al. [28], are greenest, and become red or yellow with decrease in chlorophyll content due to poor fertilization. Both the SRI and NDVI could thus be used in assessing the nutrient status for tobacco seedbed. Corrective measures could be taken if the detection has been done early enough, while at an advanced phenological stage, this response could be used to determine the size of wellfertilized seedbed area that could be available for planting [6].

Both the NDVI and SRI for T66 were greater $(P<$ $0.05)$ than those for KRK26 and KE1. The latter two (KRK 26 and KE1) had statistically similar $(P<0.05)$ reflectance values. Plant variety has significant influence on the reflective property of the plant through the physical, biochemical, and morphological characteristics of the canopy 

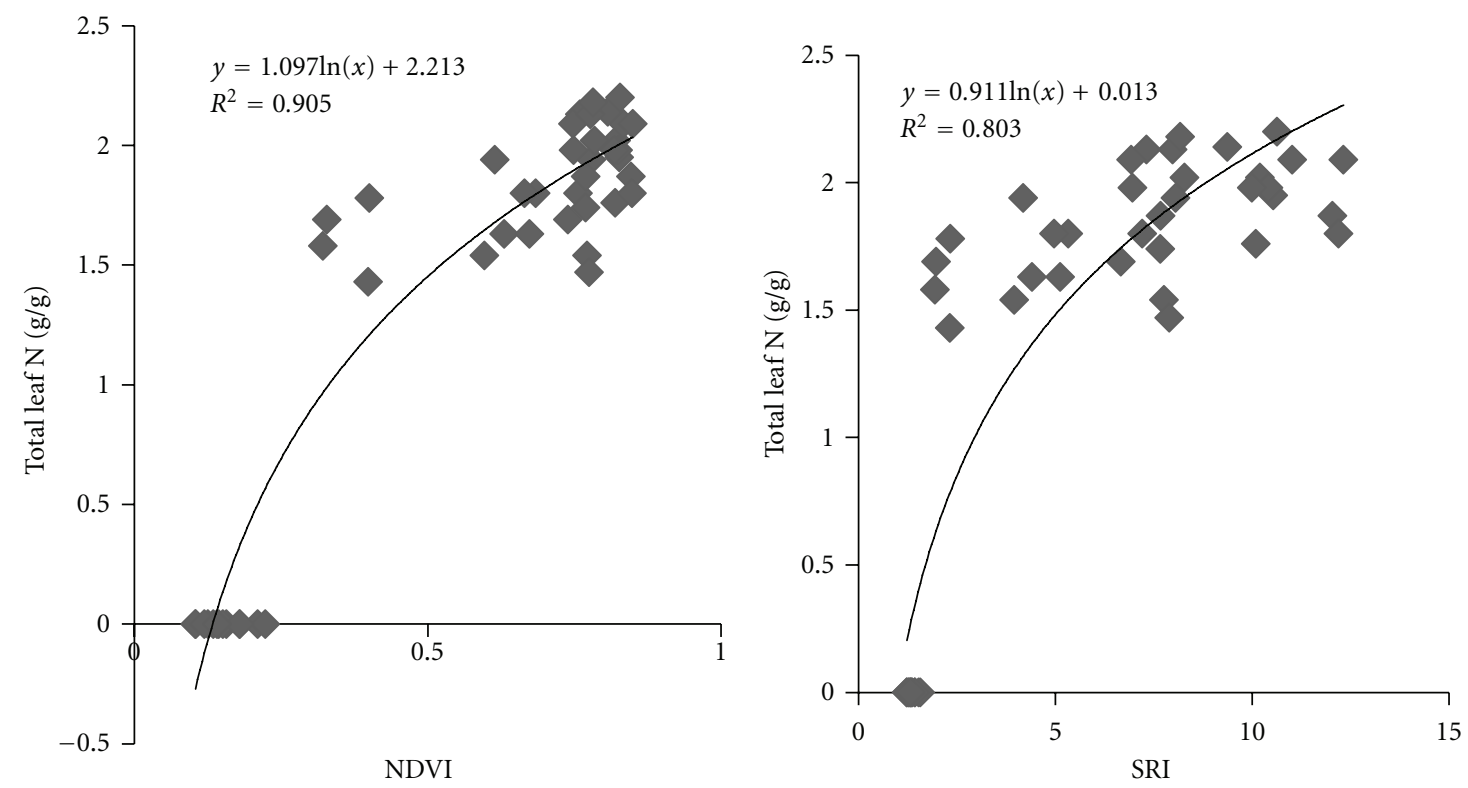

FIgURE 14: Correlation between leaf total $\mathrm{N}$ and NDVI/SRI at pulling (72 days after sowing).

TABLE 2: Summary of simple ratios for all the variety $\times$ fertilizer treatments.

\begin{tabular}{lcc}
\hline Fertilizer level & Simple ratio range & NDVI range \\
\hline 0 & $1.52-1.78$ & $0.21-0.28$ \\
50 & $1.92-5.16$ & $0.38-0.67$ \\
100 & $6.10-7.41$ & $0.72-0.76$ \\
150 & $8.34-10.50$ & $0.79-0.83$ \\
\hline
\end{tabular}

$[23,29]$. The variety T66 could be genetically more superior in biomass production. In addition it could also be easy differentiating these, and calculating their proportions in the field using the NDVI and SRI profiles.

The high seedling dry mass and height correlations with both NDVI and SRI were indicative of possible application of the two in tobacco seedling quality assessment using remote sensing. The seedling dry mass and seedling length are both measures of biomass and quality which, according to Mutanga [7], are affected by plant N status. The correlations between seedling count/tray with both NDVI $\left(r^{2}=0.626\right)$ and SRI $\left(r^{2}=0.797\right)$ were also high enough to be applicable in estimating seedling populations in a tobacco floatbed using remote sensing.

The VIs were maintained at more or less same levels between days 49 and 79 (pulling stage). Generally in the floatbed no additional nutrition is added on seedlings after day 42 , except for such cases where nutrients would have leaked out of the media. Quality and quantity estimations made after all fertilizers are applied could hence be relied on, and any repeated measurements taken would be used for verification of earlier findings.

The high correlations between NDVI and SRI with total $\mathrm{N}(0.905$ and 0.803$)$ translated to an increase in canopy reflectance as $\mathrm{N}$ concentration in the leaves decrease at low nutrient levels [30]. Past research has associated nitrogen deficiencies with decreasing amounts of chlorophyll in cotton [31], and maize [14]. The simple ration and NDVI ranges for the 100-150\% fertilizer treatments were comparable with those that were associated with high plant health and vigour in past research $[14,17]$.

\section{Conclusions}

The spectral response curve can be used to assess seedling vigour in response to fertilizer management levels. However, the reflectance values at the channels would depend on the amount of energy that falls on top of the canopy and this varies according to the time of the day, season and weather conditions. A better index should be one that minimizes the effect of the above factors. Channels 1, 2, 3 and Channel 4 had high correlation with fertilizer rate and hence can be used in tobacco seedling vigour assessment. The coefficients of determination for Channels 1, 2, and 3 and fertiliser application rates were, however, negative and treatment differences were so narrow that an experienced person could need to accurately apply these in plant vigour assessment. Channel 4, with a positive correlation could be easier to apply, but like the former 3 , the treatment differences were also narrow for easy application in plant vigour assessment.

Both the NDVI and the SRI were highly correlated with fertilizer application rates, and hence could be used in assessing nutrient status and requirements in tobacco float seedling. The two indices could clearly show the differences in the variety $\times$ fertilizer interactions. The strength of the relationship was also maintained up to the time of pulling.

The variety T 66 can be distinguished from K RK26 and $\mathrm{K}$ E1 using canopy reflectance. Since these have different yield potentials, the potential cropping areas for these could be separately determined. 
The SRI showed a stronger relationship with seedling dry mass and seedling height as well as seedling density than the NDVI, and hence could be used in seedling quality assessment. Total leaf $\mathrm{N}$ was also more linearly related with the SRI than the NDVI. There is potential in using the VI in nutrient assessment for quick implementation of corrective measures. Because of its higher correlation with seedling count/tray, the SRI can be used more accurately to estimate the quantity of seedling that can available for planting out in the field.

In tobacco float seedlings an SRI of at least 6.10 and NDVI of at least 0.72 are indicative of optimum growth vigour and health.

From the results, it could be possible to assess vigour, quality, and density of flue cured tobacco float seedling using remote sensing techniques. Further research is necessary to investigate the potential of other indices like the green NDVI, blue NDVI, NRI and the chlorophyll index in assessing tobacco seedling performance in the seedbed. The information can be used in estimating seedbed size and quantity of seedling that can be available for crop establishment, and hence produce an early season crop forecast using remote sensing.

\section{References}

[1] R. D. Jackson, "Remote Sensing of Biotic and abiotic plant stress," in Annual Review of Phytopathology, vol. 24, pp. 265287,1986

[2] Ikisan.com, "CropInformation: tobacco," 2000, http://www .ikisan.com/Crop\%20Specific/Eng/links/ap_nutrients.shtml.

[3] J. A. Moran, A. K. Mitchell, G. Goodmanson, and K. A. Stockburger, "Differentiation among effects of nitrogen fertilization treatments on conifer seedlings by foliar reflectance: a comparison of methods," Tree Physiology, vol. 20, no. 16, pp. 1113-1120, 2000

[4] M. E. Bausch, "The role of remote sensing in determining the distribution and yield of crop," Advances in Agronomy, vol. 27, pp. 271-304, 1975.

[5] N. N. Broge, M. Hvidberg, B. U. Hansen, H. S. Anderson, and A. A. Nielsen, "Analyses of spectral-biophysical relationships for a wheat canopy," in Proceedings of the 3rd International Airborne Remote Sensing Conference and Exhibition, vol. 2, pp. 373-379, 1997.

[6] J. R. Thomas and H. W. Gausman, "Leaf reflectance versus leaf chlorophyll and carotenoid concentrations for eight crops," Agronomy Journal, vol. 69, pp. 799-802, 1977.

[7] O. Mutanga, Hyperspectral remote sensing of tropical grass quality and quantity [Ph.D. thesis], Wageningen University, The Netherlands, ITC Dissertation Number 111, 2004.

[8] S. C. Liew, "Principles of remote sensing," Centre for Remote Imaging, Sensing and Processing, National University of Singapore, Singapore 119260, 2001, http://www.crisp.nus.edu $. s g / \sim$ research/tutorial/rsmain.htm.

[9] E. B. Knipling, "Physical and physiological basis for the reflectance of visible and near-infrared radiation from vegetation," Remote Sensing of Environment, vol. 1, no. 3, pp. 155159, 1970.

[10] R. D. Jackson, P. N. Slater, and P. J. Pinter, "Discrimination of growth and water stress in wheat by various vegetation indices through clear and turbid atmospheres," Remote Sensing of Environment, vol. 13, no. 3, pp. 187-208, 1983.
[11] J. U. H. Eitel, R. F. Keefe, D. S. Long, A. S. Davis, and L. A. Vierling, "Active ground optical remote sensing for improved monitoring of seedling stress in nurseries," Sensors, vol. 10, no. 4, pp. 2843-2850, 2010.

[12] C. J. Tucker, "Red and photographic infrared linear combinations for monitoring vegetation," Remote Sensing of Environment, vol. 8, no. 2, pp. 127-150, 1979.

[13] E. Boegh, H. Soegaard, N. Broge et al., "Airborne multispectral data for quantifying leaf area index, nitrogen concentration, and photosynthetic efficiency in agriculture," Remote Sensing of Environment, vol. 81, no. 2-3, pp. 179-193, 2002.

[14] G. Walburg, M. E. Baccer, C. S. T. Daughty, and T. L. Housley, "Effects of nitrogen on the growth, yield and reflectance characteristics of corn," Agronomy Journal, vol. 74, pp. 677683, 1982.

[15] G. A. Blackburn, "Remote sensing of forest pigments using airborne imaging spectrometer and LIDAR imagery," Remote Sensing of Environment, vol. 82, no. 2-3, pp. 311-321, 2002.

[16] P. J. Sellers, "Canopy reflectance, photosynthesis and transpiration.," International Journal of Remote Sensing, vol. 6, no. 8, pp. 1335-1372, 1985.

[17] S. A. Clay, C. G. Carlson, D. E. Clay et al., "Estimating nonharvested crop residue cover dynamics using remote sensing," 2006, http://www.sdstate.edu/index/directory/directorydetail.cfm?...ci.

[18] R. T. Garvin, "Yield estimation-a tool for reducing Losses," Zimbabwe Tobacco Today, vol. 9, no. 12, pp. 32-35, 19861986.

[19] K. P. Gallo and T. K. Flesch, "Large-area crop monitoring with the NOAA AVHRR: estimating the silking stage of corn development," Remote Sensing of Environment, vol. 27, no. 1, pp. 73-80, 1989.

[20] S. Moulin, A. Bondeau, and R. Delécolle, "Combining agricultural crop models and satellite observations: from field to regional scales," International Journal of Remote Sensing, vol. 19, no. 6, pp. 1021-1036, 1998.

[21] J. Nowatzki, R. Andres, and K. Kyllo, "Agricultural remote sensing basics," North Dakota State University Agriculture and University Extension, 2004, http://www.ag.ndsu.edu/.

[22] T. H. Demetriades-Shah, M. D. Steven, and J. A. Clark, "High resolution derivative spectra in remote sensing," Remote Sensing of Environment, vol. 33, no. 1, pp. 55-64, 1990.

[23] J. L. Hatfield, A. A. Gitelson, J. S. Schepers, and C. L. Walthall, "Application of spectral remote sensing for agronomic decisions," Agronomy Journal, vol. 100, no. 3, pp. S117-S131, 2008.

[24] S. L. Ustin, D. A. Roberts, J. A. Gamon, G. P. Asner, and R. O. Green, "Using imaging spectroscopy to study ecosystem processes and properties," BioScience, vol. 54, no. 6, pp. 523534, 2004.

[25] C. S. T. Daughtry, C. L. Walthall, M. S. Kim, E. B. De Colstoun, and J. E. McMurtrey, "Estimating corn leaf chlorophyll concentration from leaf and canopy reflectance," Remote Sensing of Environment, vol. 74, no. 2, pp. 229-239, 2000.

[26] A. A. Gitelson, M. N. Merzlyak, and O. B. Chivkunova, "Optical properties and non destructive estimation of anthocyanin content in plant leaves," Photochemistry and Photobiology, vol. 74, pp. 38-45, 2001.

[27] D. Casanova, G. F. Epema, and J. Goudriaan, "Monitoring rice reflectance at field level for estimating biomass and LAI," Field Crops Research, vol. 55, no. 1-2, pp. 83-92, 1998.

[28] F. Su, L. Fu, H. Chen, and L. Hong, "Balancing nutrient use for flue-cured tobacco," Better Crops, vol. 90, no. 4, pp. 23-25, 2006.

[29] T. Endo, T. Okuda, M. Tamura, and Y. Yasuoka, "Estimation of photosynthetic rate of plants from hyperspectral remote 
sensing of biochemical content," in Proceedings of the 21st Asian Conference on Remote Sensing (ACRS '00), Taipei, Taiwan, December 2000.

[30] J. L. Fridgen and J. J. Varco, "Dependency of Cotton Leaf Nitrogen, Chlorophyll, and Reflectance on Nitrogen and Potassium Availability," Agronomy Journal, vol. 96, no. 1, pp. 63-69, 2004.

[31] C. Yang, J. H. Everitt, and J. M. Bradford, "Using high resolution QuickBird satellite imagery for cotton yield estimation," in ASAE Annual International Meeting 2004, pp. 893-904, can, August 2004. 


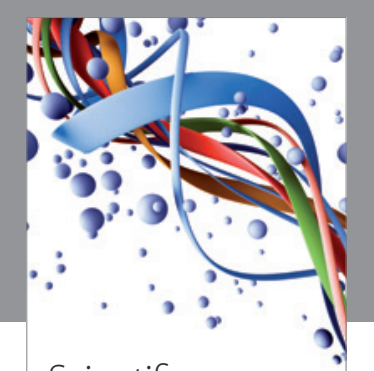

Scientifica
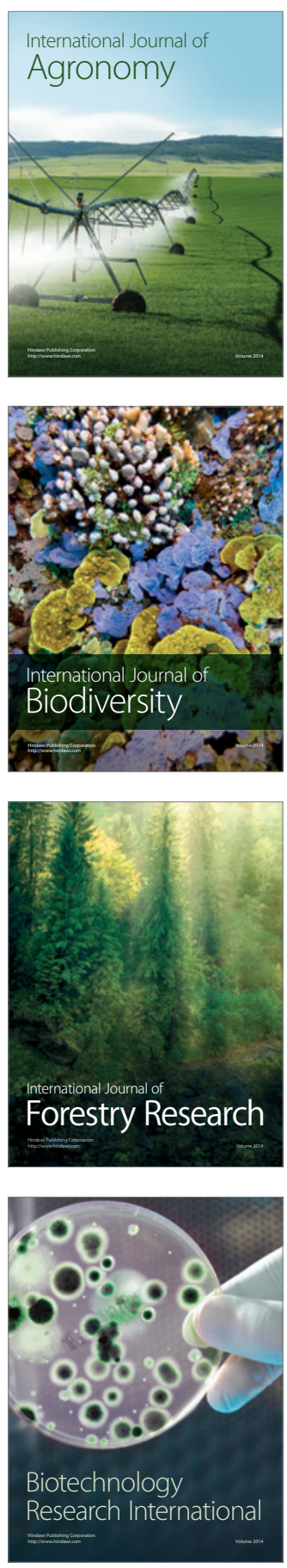
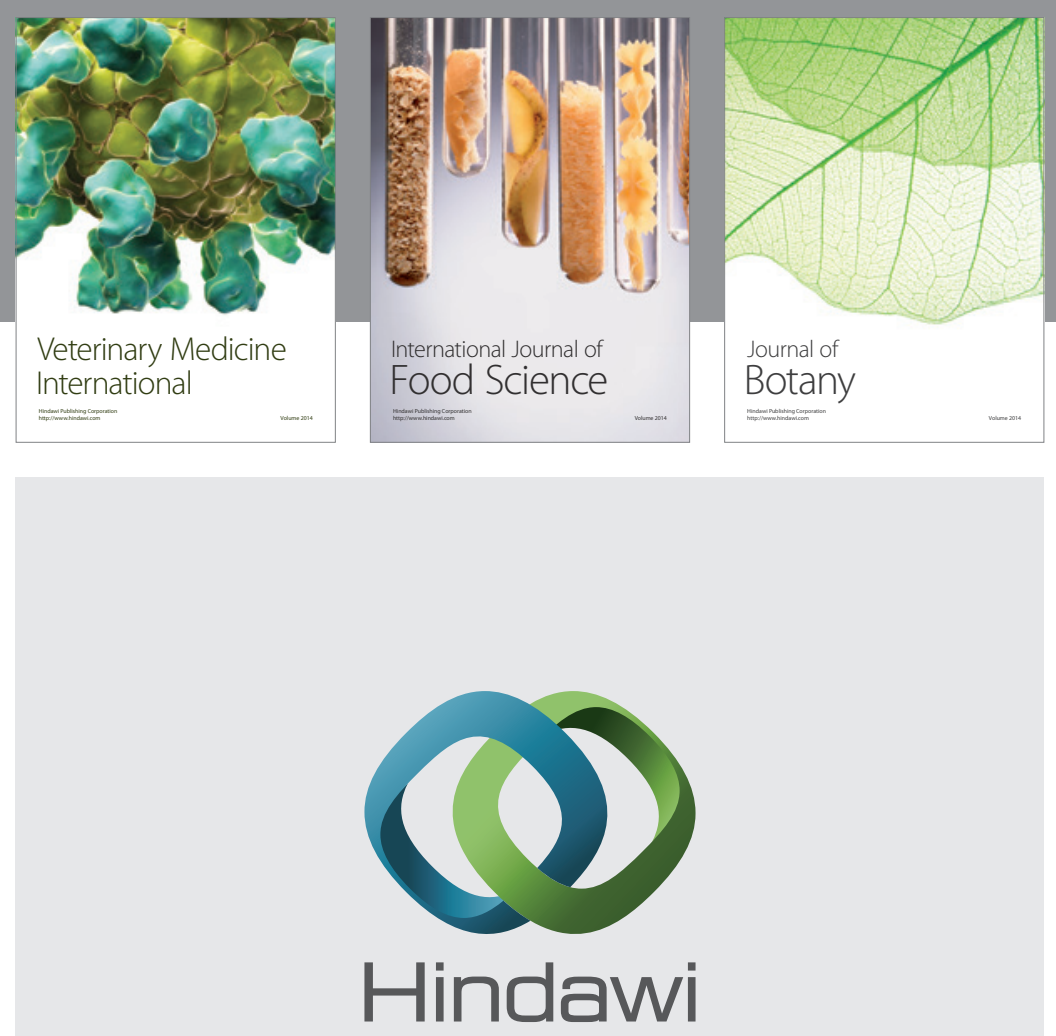

Submit your manuscripts at

http://www.hindawi.com
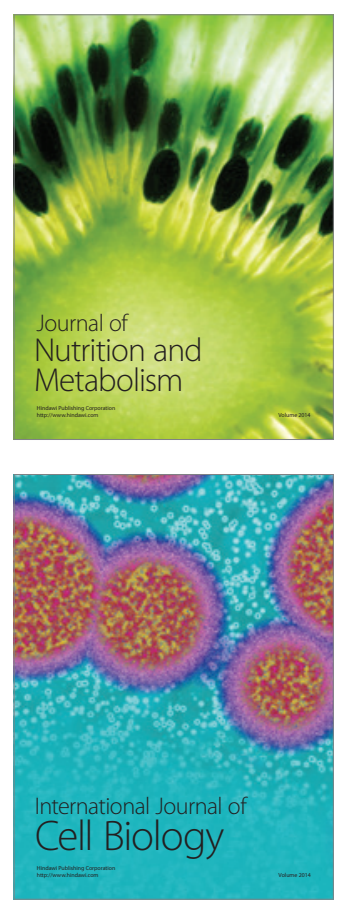
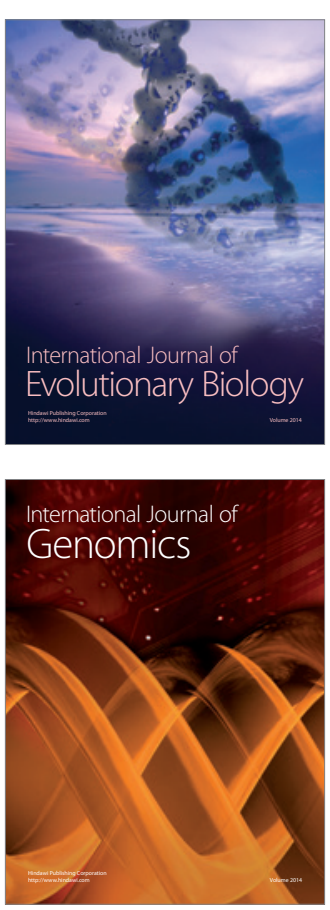
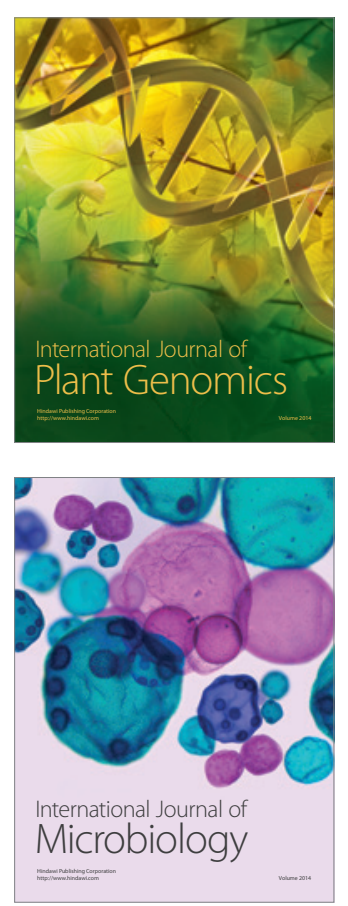

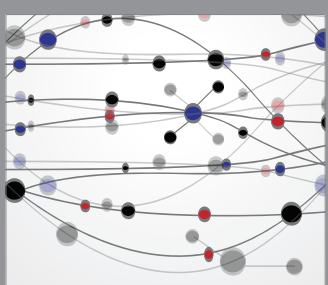

The Scientific World Journal
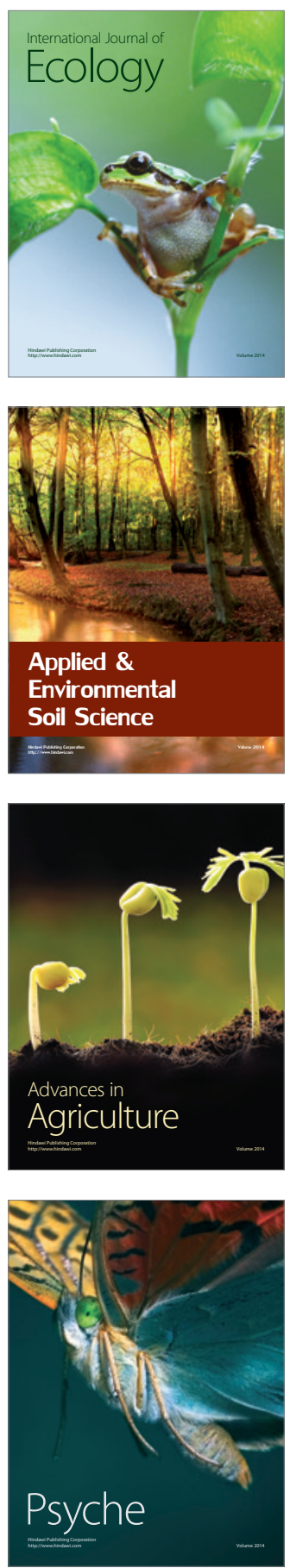